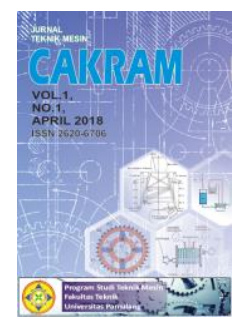

\title{
RANCANG BANGUN DAN STUDI EKSPERIMEN PEMANAS AIR TENAGA MATAHARI DENGAN REFLEKTOR BUSUR SEPEREMPAT LINGKARAN Nailul 'Atifah' ${ }^{1}$

\author{
${ }^{1}$ Program Studi Teknik Mesin, Universitas Pamulang, Jl. Surya Kencana No. 1, Tangerang Selatan, Indonesia
}

E-mail : dosen00410@unpam.ac.id

Masuk: 21 Juni 2018

Direvisi : 27 September 2018

Disetujui : 2 Oktober 2018

\begin{abstract}
Abstrak: Penelitian mengenai rancang bangun dan studi eksperimen pemanas air tenaga matahari dengan reflektor busur seperempat lingkaran telah dilaksanakan. Reflektor busur seperempat lingkaran pada penelitian ini memiliki ukuran jari-jari sebesar $60 \mathrm{~cm}$, panjang $60 \mathrm{~cm}$, terbuat dari potongan cermin dengan lebar $3 \mathrm{~cm}$ dan panjang $30 \mathrm{~cm}$. Sistem pemanas air tenaga matahari ini memiliki nilai fraksi radiasi dari reflektor parabola ke pipa absorber sebesar 5,2 \%. Pipa absorber terbuat dari pipa besi yang dicat hitam dengan diameter 1,5 inchi. Hasil percobaan menunjukkan bahwa pemanas air tenaga matahari ini dapat memanaskan air sebanyak $684 \mathrm{ml}$ dengan suhu maksimal mencapai $71^{\circ} \mathrm{C}$ pada kondisi cerah dan tidak berangin. Pemanas air tenaga matahari ini menghasilkan nilai energi termal output tertinggi sebesar 98,73 kJ. Energi termal ouput rata-rata pada sistem ini adalah sebesar 55,08 kJ dengan efisiensi termal rata-rata sebesar $31,64 \%$.
\end{abstract}

Kata kunci : pemanas air tenaga matahari, busur seperempat lingkaran, reflektor, temperatur, energi termal, efisiensi termal

Abstract: The research on design and experimental studies of solar water heater with a quarter circular arc reflector has been done. The quarter circle arc reflector in this research has radius of $60 \mathrm{~cm}$, and length of $60 \mathrm{~cm}$. This reflector is made of cut-off mirrors $3 \mathrm{~cm}$ width and $30 \mathrm{~cm}$ length. The radiation fraction value from the parabolic reflector to the absorber pipe is $5.2 \%$. The absorber pipe is made of black painted iron pipe with 1.5 inch diameter. The experimental results show that this solar water heater is able to heat $684 \mathrm{ml}$ of water with a maximum temperature of $71^{\circ} \mathrm{C}$ in bright and windless conditions. This solar energy heater has the highest thermal energy output of $98.73 \mathrm{~kJ}$. The average output thermal energy in this system is $55.08 \mathrm{~kJ}$ with an average thermal efficiency of $31.64 \%$.

Keywords : solar water heater, quarter circular arc, reflector, temperature, thermal energy, thermal efficiency

\section{PENDAHULUAN}

Indonesia merupakan negara yang memiliki sumber energi matahari yang cukup potensial dikarenakan terletak pada garis khatulistiwa. Intensitas rata-rata radiasi matahari untuk wilayah Jabodetabek adalah sekitar 4,98334-5,02111 $\mathrm{kWh} / \mathrm{m}^{2} /$ hari [1]. Teknologi pemanfaatan energi matahari melalui sitem termal salah satunya adalah dengan sistem parabolic trough. Sistem ini menggunakan reflektor berbentuk terusan palung dengan kurva berbentuk parabola dan pipa absorber yang ditempatkan di sepanjang garis fokusnya.

Prastika, dkk [2] dalam penelitiannya mengenai sistem Mini PTC (Parabolic Trough Collector) menggunakan bahan plat seng mengkilat sebagai reflector dan pipa alumunium sebagai absorber. Desain aperture reflektor $50 \mathrm{~cm}$ dan panjang $105 \mathrm{~cm}$ yang dirancang sanggup memanaskan air sebanyak $63,2 \mathrm{ml}$ dengan temperatur maksimal sebesar $54^{\circ} \mathrm{C}$. Tayade et al. [3] dalam penelitiannya melakukan perancangan PTC dengan menggunakan alumunium sebagai bahan reflektornya dan bahan pipa absorbernya, serta pipa gelas untuk mengungkung pipa absrobernya. Kenaikan suhu pada sistem yang dirancangnya mencapai suhu $32^{\circ} \mathrm{C}-55 \mathrm{C}$ selama bulan NovemberDesember 2015 di daerah Chandrapur, India (19.95 $\left.\mathrm{LU}, 79.3^{\circ} \mathrm{BT}\right)$. Berikutnya, hasil penelitian Valan Arasu dan 
Sornakumar [4] menunjukkan PTC yang dirancang dengan bahan reflector berupa solarflex foil dan absorber dengan bahan tembaga yang diselubungi dengan pipa gelas dapat menaikan suhu air dalam pipa sebesar $42^{\circ} \mathrm{C}-55^{\circ} \mathrm{C}$.

Penelitian kali ini mengadopsi sistem yang mirip dengan parabolic trough dari penelitian-penelitian sebelumnya. Namun, perbedaannya terletak pada bentuk geometri pada bagian reflektornya. Bagian reflektor pada penelitian ini berupa kurva yang berbentuk busur seperempat lingkaran. Hal ini dilatarbelakani karena lebih mudah dalam pembuatannya. Selain itu, material reflektor yang digunakan adalah cermin yang dipotong-potong. Meskipun formasi reflektor akhirnya bukanlah berbentuk kurva yang halus, namun dengan nilai reflektansi yang tinggi dari material cermin diharapkan dapat memantulkan radiasi yang cukup tinggi.

\section{PERANCANGAN}

Radiasi matahari yang mengenai reflektor cermin busur lingkaran akan dipantulkan pada titik fokusnya. Letak fokus pada cermin cekung adalah setengah dari jari-jarinya. Daya radiasi yang dipantulkan cermin pada pipa absorber dapat dinyatakan dalam persamaan berikut [5]:

$$
P_{i n}=F_{12} . r . I . A_{r}
$$

dengan:

$P_{\text {in }} \quad$ : Daya input yang diterima pipa absorber dari pantulan reflektor (Watt)

$F_{12} \quad$ : Fraksi radiasi dari reflektor parabola ke pipa absorber

$\phi \quad$ : reflektansi cermin reflektor

I $\quad$ : Intensitas matahari $\left(\mathrm{Watt} / \mathrm{m}^{2}\right)$

$A_{r} \quad$ : Luas reflektor cermin $\left(\mathrm{m}^{2}\right)$

Reflektansi reflektor yang terbuat dari cermin adalah sekitar $80 \%$ s/d $97 \%$ [3]. Jika intensitas rata-rata radiasi matahari untuk wilayah Jabodetabek adalah sekitar 4,98334-5,02111 kWh/m²/hari [1] dengan hari yang dimaksud adalah lama penyinaran matahari dari pagi sampai sore yakni sekitar 12 jam, maka dapat dikonversikan nilainya menjadi 415,278-418,426 W/m².

Sedangkan luas reflektor yang merupakan busur seperempat lingkaran dapat dihitung dengan rumus sebagai berikut:

$$
A_{r}=\frac{\pi}{2} \cdot r \cdot L
$$

dengan:

$r \quad$ : jari-jari reflektor $(\mathrm{m})$

$L \quad$ : panjang reflektor $(\mathrm{m})$

Reflektor yang digunakan dalam penelitian ini memiliki radius $60 \mathrm{~cm}$ dan panjang $60 \mathrm{~cm}$. Dengan demikian nilai $\mathrm{A}_{\mathrm{r}}$ dapat dihitung sebagai berikut:

$$
A_{r}=\frac{\pi}{2} \cdot 0,6 m \cdot 0,6 m=0,565 m^{2}
$$

Gambar 1. berikut menunjukkan sketsa pemanas air tenaga matahari dengan reflektor terusan busur seperempat lingkaran yang akan diuji: 


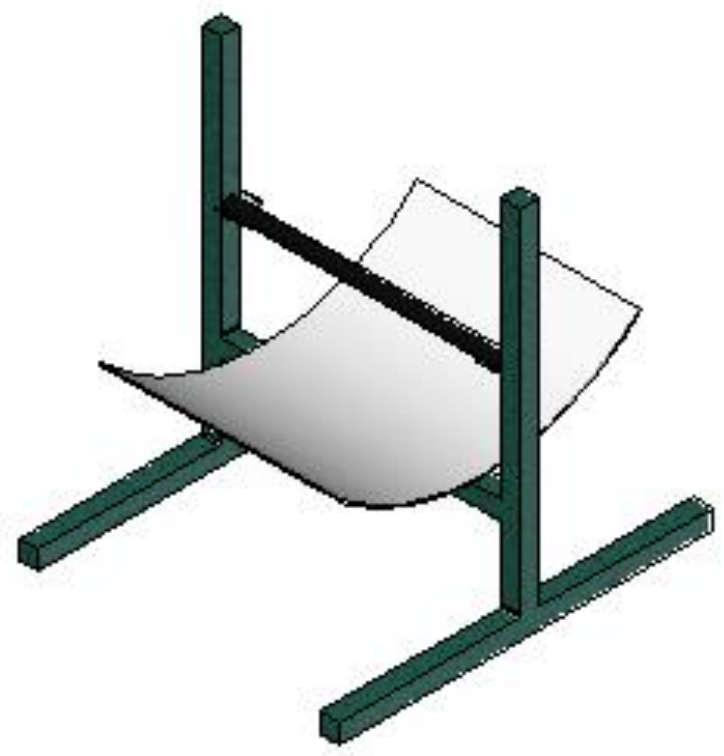

Gambar 1. Sketsa Pemanas Air Tenaga Matahari dengan Busur Seperempat Lingkaran

Jika reflektor cermin dianggap sebagai permukaan 1 dan pipa absorber dianggap sebagai permukaan 2, maka berdasarkan relasi reciprocity dapat dinyatakan dengan persamaan berikut [5]:

$F_{12}=\frac{A_{2}}{A_{1}} \cdot F_{21}$

dengan:

$\mathrm{A}_{1} \quad$ : Luas permukaan reflektor parabola persatuan panjang (m)

$\mathrm{F}_{12} \quad$ : Fraksi radiasi dari reflektor parabola ke pipa absorber

$\mathrm{A}_{2} \quad$ : Luas permukaan pipa absorber persatuan panjang $(\mathrm{m})$

$\mathrm{F}_{21} \quad$ : Fraksi radiasi dari pipa absorber ke reflektor parabola

Gambar 2. berikut menunjukkan penampang reflektor busur parabola dan pipa absorber

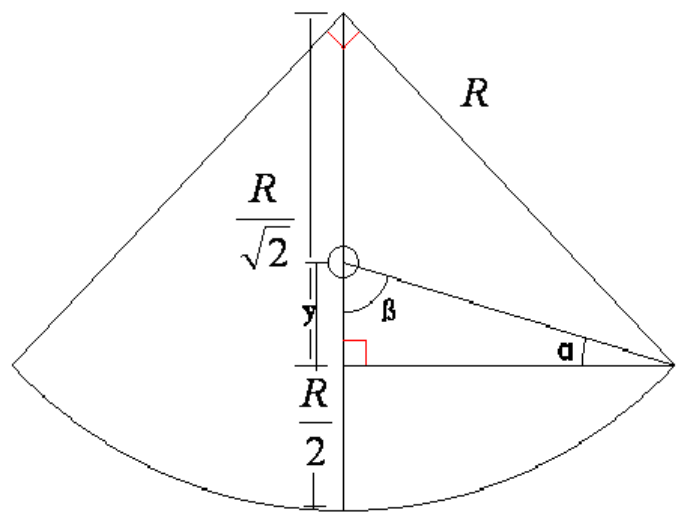

Gambar 2. Penampang Reflektor Busur Parabola dan Pipa Absorber 
$y, \alpha, \beta$ merupakan besaran geometri yang terdapat pada Gambar 2. di atas.

Nilai $F_{12}$ dapat diperoleh dengan analisis geometri sebagai berikut:

$$
\begin{aligned}
& y=\frac{R}{\sqrt{2}}-\frac{R}{2}=\frac{R}{2}(\sqrt{2}-1)=0,207 . \mathrm{R} \\
& \alpha=\tan ^{-1}\left(\frac{y}{\frac{R}{\sqrt{2}}}\right)=\tan ^{-1}\left(\frac{0,207 R}{0,707 . R}\right)=\tan ^{-1}(0,293)=16,32^{0} \\
& \beta=90^{0}-\alpha=90^{0}-16,32^{0}=73,68^{0}
\end{aligned}
$$

Nilai $F_{21}$ dapat diperoleh dengan rumus berikut:

$$
F_{21}=\frac{2 \beta}{360^{0}}=\frac{\beta}{180^{0}}=\frac{73,68^{0}}{180^{0}}=0,409
$$

Diameter pipa absorber yang digunakan adalah 1,5 inchi= 3,81 $\mathrm{cm}$ dan radius cermin reflektor adalah 60 cm. Maka nilai $A_{1}$ dan $A_{2}$ dapat dihitung dengan penjabaran sebagai berikut:

$$
\begin{aligned}
& A_{1}=\frac{\pi}{2} \cdot R=\frac{\pi}{2} \cdot 0,6 m=0,942 m \\
& A_{2}=\pi \cdot d=\pi \cdot 0,00381 \mathrm{~m}=0,120 \mathrm{~m}
\end{aligned}
$$

Dengan mensubstitusikan nilai $F_{21}, \mathrm{~A}_{1}$ dan $\mathrm{A}_{2}$ ke dalam persamaan (3), maka:

$$
F_{12}=\frac{A_{2}}{A_{1}} \cdot F_{21}=\frac{0,120 m}{0,942 m} \cdot 0,409=0.052
$$

Tidak semua radiasi yang dipantulkan oleh reflektor cermin diterima oleh pipa absorber. Faktor radiasi yang diterima oleh pipa berdasarkan perhitungan di atas adalah 0,052. Jika Intensitas rata-rata radiasi matahari untuk wilayah Jabodetabek adalah sekitar 4,98334-5,02111 kWh/m²/hari [1] dengan hari yang dimaksud adalah lama penyinaran matahari dari pagi sampai sore yakni sekitar 12 jam, maka dapat disetarakan nilainya dengan 415,278$418,426 \mathrm{~W} / \mathrm{m}^{2}$. Dengan demikian daya input pada sistem ini jika menggunakan nilai intensitas matahari terendah yaitu $415 \mathrm{~W} / \mathrm{m}^{2}$ adalah sebagai berikut:

$$
\begin{aligned}
& P_{i n}=F_{12} \cdot \phi \cdot I \cdot A_{r} \\
& P_{i n}=0,052 \cdot 0,8 \cdot 415 \mathrm{~W} / \mathrm{m}^{2} \cdot 0,565 \mathrm{~m}^{2} \\
& P_{\text {in }}=9,76 \mathrm{~W}
\end{aligned}
$$


Dalam hal ini nilai intensitas matahari yang digunakan dalam perhitungan adalah nilai terendah yaitu 415 $\mathrm{W} / \mathrm{m}^{2}$. Nilai reflektansi cermin $\phi$ yang digunakan adalah $80 \%$ yang merupakan nilai minimum data reflektasi cermin yang ada di pasaran yakni 80\%-97\% [6].

Tidak semua daya input dikonversi seluruhnya menjadi panas. Akan tetapi terjadi heat loss (kerugian panas) ke lingkungan baik berupa konveksi maupun radiasi akibat adanya perbedaan temperatur antara pipa absorber dengan lingkungan.

Heat loss dengan mekanisme konveksi dijabarkan dengan persamaan berikut [7]:

$$
q_{\text {conv }}=h \cdot A_{p} \cdot\left(T_{p}-T_{s}\right)
$$

dengan:

$\mathrm{q}_{\text {conv }} \quad$ : Laju perpindahan panas konveksi (W)

$\mathrm{h} \quad$ : Koefisien perpindahan panas konveksi $\left(\mathrm{W} / \mathrm{m}^{2} . \mathrm{K}\right)$

$\mathrm{A}_{\mathrm{p}} \quad$ : Luas pipa absorber $\left(\mathrm{m}^{2}\right)$

$\mathrm{T}_{\mathrm{p}} \quad$ : Temperatur pipa absorber $(\mathrm{K})$

$\mathrm{T}_{\mathrm{s}} \quad$ : Temperatur lingkungan sekitar $(\mathrm{K})$

Sedangkan heat loss dengan mekanisme perpindahan panas radiasi dari pipa absorber ke lingkungan dapat dijabarkan dengan persamaan berikut [7]:

$$
q_{\text {rad }}=\varepsilon \cdot \sigma \cdot A_{p}\left(T_{p}^{4}-T_{s}^{4}\right)
$$

dengan:

$\mathrm{q}_{\mathrm{rad}} \quad$ : Laju perpindahan panas radiasi (W)

$\varepsilon \quad:$ Emisivitas pipa absorber

$\sigma \quad$ : Konstanta Stefan Boltzman $\left(5,67.10^{-8} \mathrm{~W} / \mathrm{m}^{2} . \mathrm{K}^{4}\right)$

Total kerugian panas total konveksi dan radiasi adalah:

$q_{\text {loss }}=q_{\text {conv }}+q_{\text {rad }}$

dengan:

$\mathrm{q}_{\mathrm{loss}} \quad$ : Total laju kerugian perpindahan panas (W)

Dengan demikian daya yang berguna untuk memanaskan air di dalam pipa absorber adalah:

$$
P_{\text {out }}=P_{\text {in }}-q_{\text {loss }}
$$

dengan:

$P_{\text {out }} \quad$ : Daya output yang berguna untuk memanaskan air (W)

Dengan demikian efisiensi thermal dari sistem pemanas air tenaga matahari dapat ditentukan dengan persamaan berikut [8]:

$$
\eta=\frac{P_{o u t}}{P_{\text {in }}} x 100 \%
$$


Dengan:

$\eta \quad$ : Efisensi termal pemanas air tenaga matahari

Nilai $\eta$ juga dapat dihitung dengan perbandingan energi input dan energi output secara total selama rentang waktu operasi. Maka efisiensi juga dapat dinyatakan dengan persamaan berikut:

$\eta=\frac{E_{\text {out }}}{E_{\text {in }}} x 100 \%$

dengan:

$E_{\text {in }} \quad$ : Energi input (Joule)

Eout : Energi output (Joule)

Energi input dapat ditentukan berdasarkan persamaan berikut:

$E_{\text {in }}=P_{\text {in }} . t$

dengan:

t $\quad$ : Waktu operasi (sekon)

Sedangkan energi output dapat ditentukan dari pengukuran temperatur air pada pipa absorber. Dari data pengukuran temperatur air akan didapatkan grafik dinamik temperatur air terhadap waktu.

Energi termal output ini merupakan panas sensibel yang menyebabkan kenaikan temperatur air dan dapat dinyatakan dengan persamaan berikut [8]:

$$
E_{\text {out }}=m \cdot c_{p} \cdot \Delta T
$$

dengan:

$\mathrm{m} \quad$ : Massa air yang dipanaskan $(\mathrm{kg})$

$c_{p} \quad$ : Kapasitas panas air $\left(4,186 \mathrm{~kJ} / \mathrm{kg} .{ }^{0} \mathrm{C}\right)$

$\Delta T \quad$ : Kenaikan temperatur air $\left({ }^{\circ} \mathrm{C}\right)$

Perhitungan $\mathrm{m}$ yang merupakan massa air dijabarkan sebagai berikut:

$m=\rho \cdot \frac{\pi D^{2}}{4} \cdot L$

dengan:

$\rho \quad$ : Massa jenis air $(\mathrm{kg} / \mathrm{m} 3)$

D $\quad$ : Diameter pipa absorber (m)

L $\quad$ : Panjang pipa absorber (m)

Sistem pemanas air ini memiliki pipa absorber dengan diameter $3,81 \mathrm{~cm}$ dan panjang $60 \mathrm{~cm}$. Air yang dipanaskan dalam pipa absorber ini terisi penuh. Dengan demikian dari perhitungan geometri volume air yang dipanaskan pada pengujian ini adalah sebesar:

$V=\frac{\pi D^{2}}{4} \cdot L=\frac{\pi \cdot(0,0381)^{2}}{4} \cdot 0,6 m^{3}=6,84 \cdot 10^{-4} m^{3}=684 m L$ 
Jika dikonversi menjadi satuan massa air dengan densitas air sekitar $997 \mathrm{~kg} / \mathrm{m}^{3}$ [7], maka massa air yang dipanaskan adalah sebesar:

$$
m=\rho \cdot \frac{\pi D^{2}}{4} \cdot L=997^{\mathrm{kg}} / \mathrm{m}^{3} \cdot 6,84 \cdot 10^{-4} \mathrm{~m}^{3}=0,682 \mathrm{~kg}
$$

Penelitian ini dilaksanakan melalui studi eksperimen dimana sistem pemanas air ini adalah berupa sistem batch, dimana air yang ditempatkan di dalam pipa dalam kondisi tidak mengalir. Pengujian dilakukan dengan mengukur kenaikan temperatur air dalam pipa dari jam efektif matahari terbit yaitu pada pukul $10.00 \mathrm{~s} / \mathrm{d}$ pukul 15.00. Temperatur air diukur setiap 15 menit sekali. Dari hasil pengukuran akan diperoleh besarnya energi output yakni panas sensibel yang berguna untuk menaikkan temperatur air.

\section{HASIL DAN PEMBAHASAN}

Pemanas air tenaga matahari dengan reflektor berbentuk busur seperempat lingkaran yang dirancang dan diuji di penelitian ini ditunjukkan pada foto pada Gambar 3. berikut:

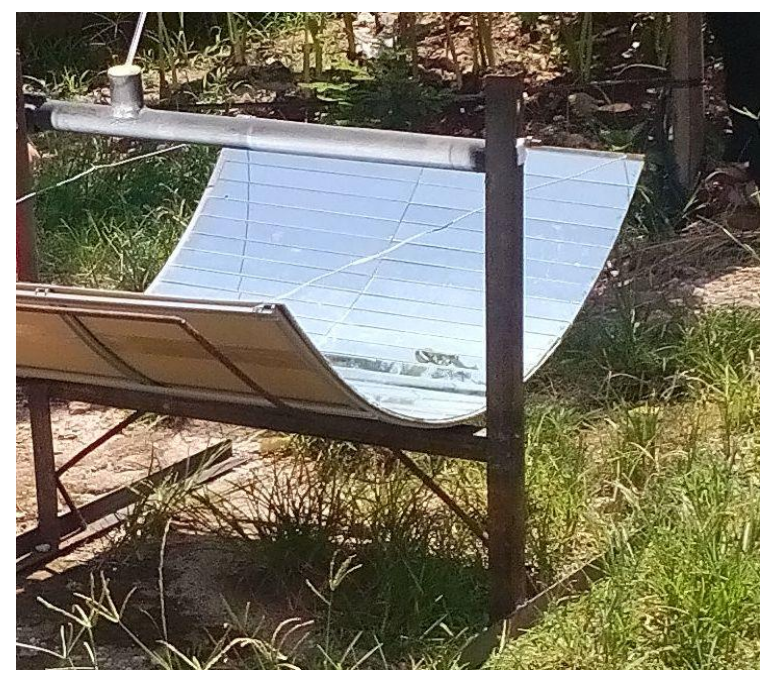

Gambar 3. Pemanas Air Tenaga Matahari dengan Reflektor Busur Seperempat Lingkaran

Gambar 4. menyajikan grafik hasil pengukuran temperatur air di dalam pipa absorber pada pemanas air tenaga matahari dengan reflektor busur seperempat lingkaran dimana pengujian dilakukan dengan temperatur air dalam pipa dari jam efektif matahari terbit yaitu pada pukul $10.00 \mathrm{~s} / \mathrm{d}$ pukul 15.00. Temperatur air diukur setiap 15 menit sekali. Pengujian dilaksanakan sebanyak 3 kali pada cuaca cerah tanpa angin.

Dari hasil pengukuran tersebut dapat dilihat bahwa temperatur air tertinggi dicapai pada temperatur $71^{\circ} \mathrm{C}$ pada menit ke 225 yakni pada pukul 13.45 WIB. Dan setelah menit ke 225 tersebut, temperatur air kembali turun. Temperatur air tertinggi di dalam pipa absorber justru tidak terjadi pada waktu puncak intensitas radiasi matahari yakni sekitar pukul 12.00. Hal ini disebabkan adanya efek heat loss (kerugian panas) dari pipa absorber ke lingkungan. Pada pukul 12.00 temperatur lingkungan sekitar juga relatif tinggi, sehingga selisih temperatur dari pipa absorber dan lingkungan juga rendah. Dengan demikian laju perpindahan panas dari pipa absorber ke lingkungan tidak terlalu tinggi. 


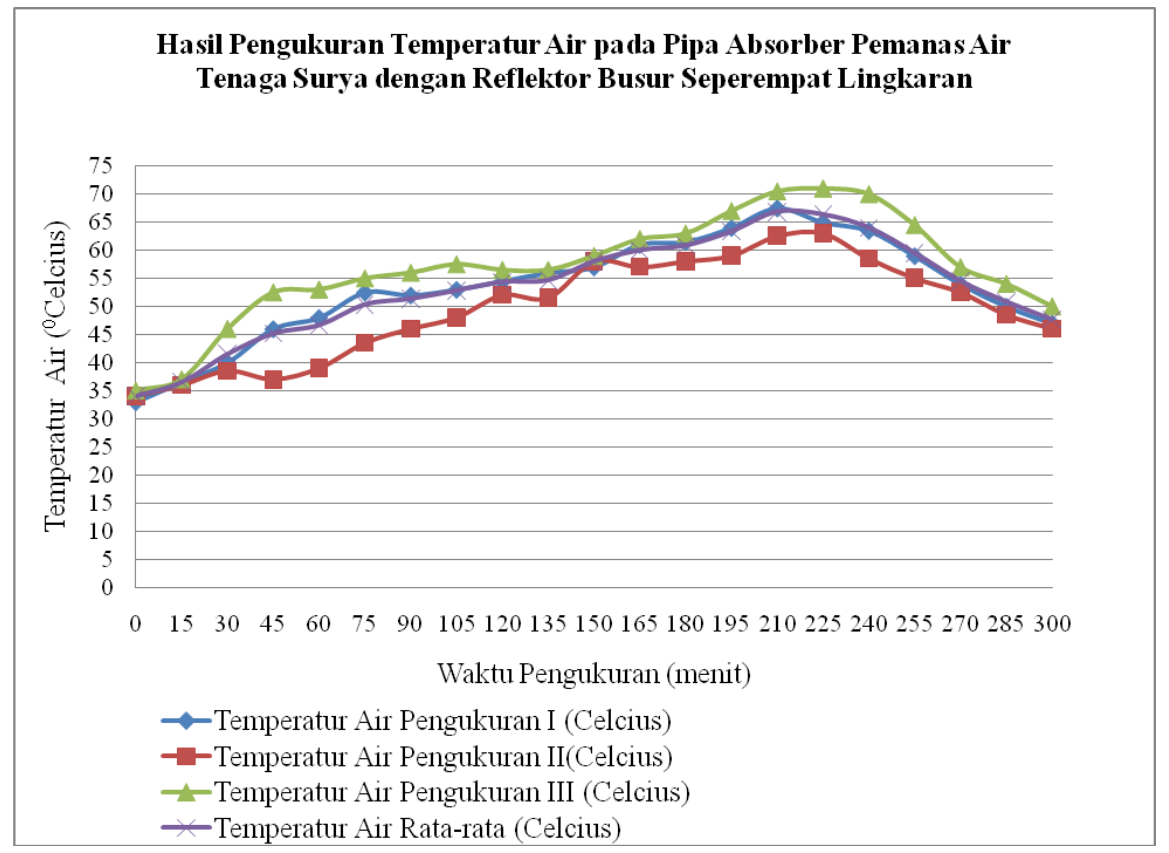

Gambar 4. Grafik Hasil Pengukuran Temperatur Air di Dalam Pipa Absorber pada Pemanas Air Tenaga Matahari dengan Reflektor Busur Seperempat

Temperatur air meningkat pada saat mendekati waktu tersebut (pukul 13.45 WIB). Hal ini juga disebabkan oleh adanya akumulasi panas air di dalam pipa absorber. Namun setelah melewati waktu tersebut temperatur air mengalami penurunan. Hal ini disebabkan karena adanya penurunan temperatur lingkungan sekitar sehingga menyebabkan selisih temperatur air dengan lingkungan meningkat. Dengan demikian laju heat loss (kerugian panas) dari pipa absorber ke lingkungan juga meningkat. Jika dibandingkan dengan hasil penelitian sebelumnya [2] yang menggunakan sistem PTC (Parabolic Trough Collector) berbahan plat seng mengkilat dengan desain aperture reflektor $50 \mathrm{~cm}$ dan panjang $105 \mathrm{~cm}$ yang memanaskan air sebanyak 63,2 ml dengan temperatur maksimal sebesar $54^{0} \mathrm{C}$, maka desain pada penelitian ini memiliki performa yang lebih baik. Desain pemanas air tenaga matahari pada peneltian ini sanggup memanaskan air lebih banyak yakni $684 \mathrm{ml}$ dengan suhu yang lebih tinggi mencapai $71{ }^{\circ} \mathrm{C}$. Meskipun demikian sistem pemanas air yang dirancang pada penelitian ini belum sanggup untuk mendidihkan air dan menghasilkan uap air.

Berdasarkan perhitungan dari persamaan (4), daya input $P_{\text {in }}$ diperoleh sebesar 9,67 W dan waktu operasi dalam rentang 5 jam. Dengan demikian energi input dapat dihitung berdasarkan persamaan (11) adalah sebagai berikut:

$E_{\text {in }}=P_{i n} . t=9,67 W \cdot 5 \cdot 3600 s=174,06 \mathrm{~kJ}$

Hasil perhitungan energi output termal berdasarkan persamaan (11), (12) dan temperatur air rata-rata disajikan melalui grafik pada Gambar 5. berikut: 


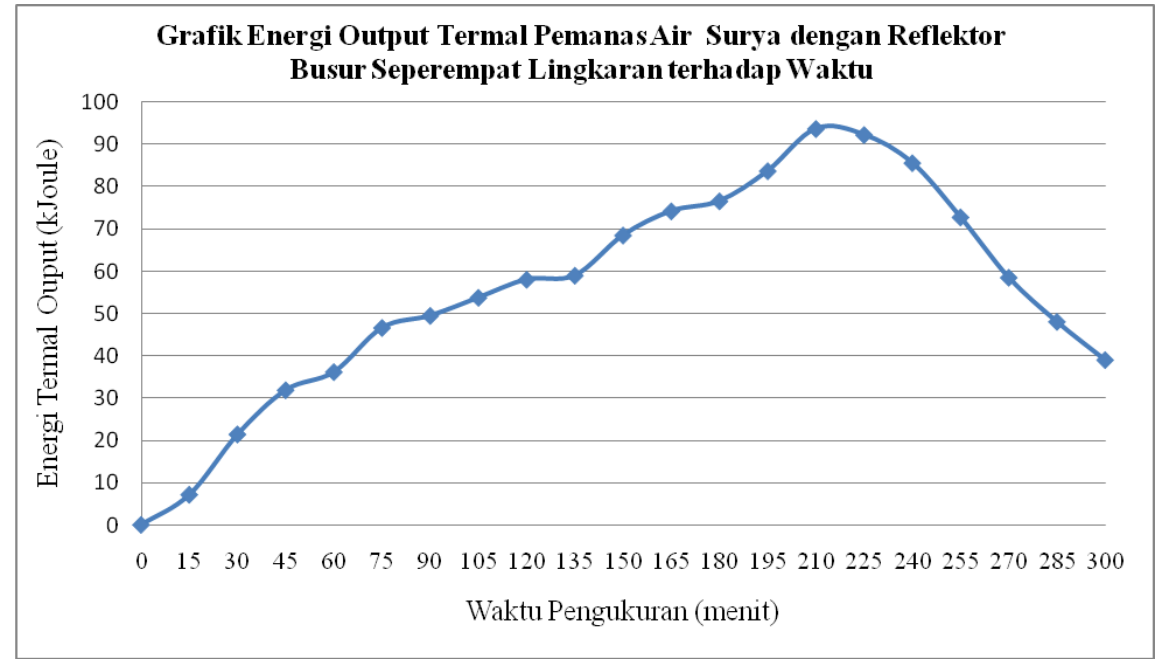

Gambar 5. Grafik Energi Termal Output Pemanas Air Tenaga Matahari dengan Reflektor Busur Seperempat Lingkaran terhadap Waktu

Dari hasil perhitungan energi termal output tersebut, diperoleh nilai energi output tertinggi sebesar 98,73 kJ. Sedangkan energi termal ouput rata-rata dalam rentang waktu pengujian selama 5 jam dari pukul 10.00 sampai dengan pukul 15.00 adalah sebesar 55,08 kJ. Dengan demikian dapat ditentukan besarnya efisensi termal rata-rata dari sistem pemanas air tenaga matahari dengan reflektor busur seperempat lingkaran ini dengan perhitungan sebagai berikut:

$$
\eta=\frac{E_{\text {out }}}{E_{\text {in }}} \times 100 \%=\frac{55,08 k J}{174,06 k J} \times 100 \%=31,64 \%
$$

Efisiensi termal pada sistem pemanas air matahari ini kurang dari 50\% atau dapat dikatakan masih relatif rendah. Hal ini disebabkan karena desain pada pipa absorber belum dilengkapi dengan mekanisme cover perangkap panas transparan yang dapat menahan panas yang telah diterima absorber sehingga mengurangi laju perpindahan panas dari pipa absorber ke lingkungan. Selain itu desain reflektor yang disusun dari cermin yang dipotong-potong memang tidak menghasilkan kurva busur seperempat lingkaran yang halus, meskipun memiliki nilai reflektansi yang relatif tinggi. Sehingga untuk kedapannya perlu dipertimbangkan mengenai pemilihan bahan reflektor yang melengkung halus namun memiliki reflektansi yang reltif tinggi seperti dari bahan stainless steel mirror. Dengan pengembangan desain selanjutnya diharapkan dapat meningkatkan efisiensi termalnya sehingga dapat mendidihkan air dan menghasilkan uap air.

\section{KESIMPULAN}

Dari hasil penelitian ini dapat ditarik kesimpulan sebagai berikut:

1. Pemanas air tenaga matahari dengan reflektor busur seperempat lingkaran berjari-jari $60 \mathrm{~cm}$, panjang $60 \mathrm{~cm}$ dengan pipa absorber berdiamater 1,5 inchi ini memiliki nilai fraksi radiasi dari reflektor parabola ke pipa absorber sebesar $5,2 \%$

2. Pemanas air tenaga matahari dengan reflektor busur seperempat lingkaran pada penelitian ini dapat memanaskan air sebanyak $684 \mathrm{ml}$ dengan suhu maksimal sebesar $71^{\circ} \mathrm{C}$ pada kondisi cerah tidak berangin dan dicapai pada waktu sekitar pukul 13.45 WIB. 
3. Desain pemanas air tenaga matahari dengan reflektor busur seperempat lingkaran pada penelitian ini yang relatif lebih mudah dirakit dan dengan ukuran yang tidak jauh berbeda dengan penelitian terdahulu yang menggunakan kurva parabola, menunjukkan performa termal yang jauh lebih tinggi meskipun belum sanggup menghasilkan uap air.

4. Pemanas air tenaga matahari dengan reflektor busur seperempat lingkaran pada penelitian ini menghasilkan nilai energi termal output tertinggi sebesar $98,73 \mathrm{~kJ}$, energi termal ouput rata-rata sebesar 55,08 $\mathrm{kJ}$ serta efisiensi termal rata-rata sebesar $31,64 \%$

\section{DAFTAR PUSTAKA}

1. Vetri Nurliyanti, Marlina Pandin, Bono Pranoto, "Pembuatan Peta Potensi Energi Matahari”. M\&E, Vol.10, No.4,Desember 2012

2. Lintang Ratri Prastika, dkk, 2015, Desain, Perakitan dan Uji Coba Mini Parabolic Trough Collector (PTC) Sederhana. Prosiding SKF, Institut Teknologi Bandung, Bandung.

3. M.G. Tayade, R. E. Thombre, S. Dutt, 2015. Int. Journal of Scientific and Research Publications 5 (1), 1-5

4. A. Valan Arasu and S. T. Sornakumar, 2006. Thermal Science 10 (2), 167-174

5. J.P. Holman, Heat Transfer, Mc Graw-Hill, New York, U.S.A, 1986.

6. Stephanie Meyan, Eckhard Lupfert "Standardization of Solar Mirror Reflectance Robin Test". National Renewable Energy Laboratory. SolarPACES, France, 2010.

7. Incropera, Frank.P, 1985, Fundamentals of Heat Transfer and Mass Tansfer, Second Edition, John Willey \&Sons, New York

8. Arora, C.P., 1998, Thermodynamics, Mc Graw-Hill Publishing Company, New York 